\title{
Strain Measurement on Composites: Errors due to Rosette Misalignment
}

\author{
A. Ajovalasit, A. Mancuso and N. Cipolla \\ Dipartimento di Meccanica e Aeronautica (DIMA) and Composite Materials Research Centre (CIRMAC), University of Palermo, \\ Viale delle Scienze Palermo, Italy
}

\begin{abstract}
Electrical resistance strain gauges are increasingly used for the determination of the strain field in composite components. The effect of the angular misalignment of a strain gauge rosette on the determination of the strains in a composite material is investigated in this paper. The theoretical analysis shows that the strain error along the principal material directions depends on the difference of principal strains, on the angular misalignment of the rosette and on the angle between the maximum principal strain and the fibre direction. The paper also shows experimental evidence for the theoretical analysis.
\end{abstract}

KEY WORDS: composites, strain gauges, misalignment error

\section{NOTATION}

$E_{1}, E_{2} \quad$ Young's moduli along the principal material axes

$G_{12} \quad$ Shear modulus

$r \quad$ Ratio between principal strains $\left(=\varepsilon_{q} / \varepsilon_{p}\right)$

$\beta \quad$ Misalignment angle of the rosette

$\varepsilon_{1}, \varepsilon_{2}, \gamma_{12} \quad$ Strains along the principal directions 1,2 of the composite lamina

$\varepsilon_{1}^{\prime}, \varepsilon_{2}^{\prime}, \gamma_{12}^{\prime} \quad$ Apparent values of strains $\varepsilon_{1}, \varepsilon_{2}, \gamma_{12}$ when a misaligned rosette is used

$\varepsilon_{\mathrm{a}}, \varepsilon_{\mathrm{b}}, \varepsilon_{\mathrm{c}} \quad$ Strains measured by grids $\mathrm{a}, \mathrm{b}$ and $\mathrm{c}$ of an aligned rosette

$\varepsilon_{\mathrm{a}}^{\prime}, \varepsilon_{\mathrm{b}}^{\prime}, \varepsilon_{\mathrm{c}}^{\prime} \quad$ Strains measured by grids $\mathrm{a}, \mathrm{b}$ and $\mathrm{c}$ of a misaligned rosette

$\varepsilon_{p}, \varepsilon_{q} \quad$ Principal strains $\left(\varepsilon_{p} \geq \varepsilon_{q}\right)$

$\varepsilon_{x}, \varepsilon_{y}, \gamma_{x y} \quad$ Cartesian components of strains

\section{Introduction}

Composite materials are increasingly used in structural components. As a consequence, experimental stress analysis methods are more often used in order to determine the mechanical properties of these materials and to measure the strain field in composite components. In this context, the use of electrical resistance strain gauges for testing composite materials is also increasing. A review of strain gauge technology as applied to composite materials is reported in Ref. [1] as far as the gauge bonding procedure, transverse sensitivity effect, errors due to gauge misalignment and temperature sensitivity are concerned.

$\begin{array}{ll}\varphi_{\varepsilon} & \begin{array}{l}\text { Angle between the fibre direction } 1 \text { and the } \\ \text { maximum principal strain } \varepsilon_{p}\end{array} \\ \varphi_{\varepsilon}^{\prime} & \begin{array}{l}\text { Apparent value of angle } \varphi_{\varepsilon} \text { when a } \\ \text { misaligned rosette is used }\end{array} \\ \varphi_{\sigma} & \begin{array}{l}\text { Angle between the fibre direction } 1 \text { and the } \\ \text { maximum principal stress } \sigma_{p}\end{array} \\ v_{12}, v_{21} \quad \begin{array}{l}\text { Major and minor Poisson's ratios along } \\ \text { the principal material axes }\end{array} \\ \theta_{1} \quad \begin{array}{l}\text { Angle between the fibre direction and the } \\ \text { rosette reference axis (gauge } a \text { axis) }\end{array} \\ \theta_{p} \quad \begin{array}{l}\text { Angle between the maximum principal strain } \\ \varepsilon_{p} \text { and the gauge } a \text { axis }\end{array} \\ \theta_{p}^{\prime} \quad \begin{array}{l}\text { Apparent value of angle } \theta_{p} \text { when a } \\ \text { misaligned rosette is used }\end{array} \\ \quad \begin{array}{l}\text { Principal stresses }\left(\sigma_{p} \geq \sigma_{q}\right)\end{array}\end{array}$

Other aspects related to the use of strain gauges on composites are reported in Refs [2-6].

This paper is concerned with the misalignment of gauges. In particular, the influence of the angular misalignment on strain measurement is well known [7-11] as far as single strain gauges and rosettes, both plane and three-dimensional are concerned. Although the strain is a purely geometric quantity, that is independent of the material properties, the anisotropic behaviour of composite materials requires special consideration, as shown by Refs $[1,12,13]$ for single strain gauges and for two element rectangular rosettes. The purpose of this research is to extend the conclusions of the previous cited papers 
$[1,12,13]$ to the case of a misaligned three gauge rosette mounted on a composite material.

It is well known that, independent of the nature (isotropic or anisotropic) of the material, the misalignment of a three gauge rosette as a whole influences:

- the measured strains $\varepsilon_{\mathrm{a}}, \varepsilon_{\mathrm{b}}, \varepsilon_{\mathrm{c}}$;

- the Cartesian components of strains $\varepsilon_{x}, \varepsilon_{y}, \gamma_{x y}$ inferred from the gauges measurement;

- the angle $\theta_{p}$ between the gauge $a$ axis and the maximum principal strain $\varepsilon_{p}$;

whereas it does not influences the values of the principal strains $\varepsilon_{p}$ and $\varepsilon_{q}$ [9].

In composite materials however the strains of interest are usually those along the principal axes of the material. Since the principal material directions, 1 , 2 , do not coincide in general with the principal strain directions, $p, q$, an error occurs on the determination of the strains $\varepsilon_{1}, \varepsilon_{2}, \gamma_{12}$ along the material directions 1,2 .

The paper focuses on the errors not considered in the previous literature. To this end both theoretical analysis and experimental evidence of the effect of misaligned rosettes are shown. In particular, formulas of strain error for three gauge rosettes are given; furthermore, some experimental results obtained with fibreglass specimens instrumented with both aligned and misaligned rosettes are reported.

\section{Theory}

\section{Review of strain analysis on composites}

In a homogeneous, elastic and orthotropic lamina subjected to a plane stress field, the principal strain $\left(\varepsilon_{p}, \varepsilon_{q}\right)$ directions no longer coincide in general with either the principal stress $\left(\sigma_{p}, \sigma_{q}\right)$ directions, or the principal material directions 1,2 . In particular, the angle $\varphi_{\varepsilon}$ between the fibre direction 1 and the maximum principal strain, $\varepsilon_{p}$, is related to the angle $\varphi_{\sigma}$, between the fibre direction and the maximum principal stress, $\sigma_{p}$ (Figure 1) by the following relation $[14,15]$ :

$\tan 2 \varphi_{\varepsilon}$

$=\frac{\left(1-\sigma_{q} / \sigma_{p}\right) G_{12}^{-1} \tan \varphi_{\sigma}}{E_{1}^{-1}\left(1+v_{12}\right)\left[1+\left(\sigma_{q} / \sigma_{p}\right) \tan ^{2} \varphi_{\sigma}\right]-E_{2}^{-1}\left(1+v_{21}\right)\left[\left(\sigma_{q} / \sigma_{p}\right)+\tan ^{2} \varphi_{\sigma}\right]}$

where $E_{1}, E_{2}$ are the Young's moduli along the principal material axes, $v_{12}$ is the major Poisson's ratio, $v_{21}$ is the minor Poisson's ratio $\left(v_{21}=v_{12} E_{2} / E_{1}\right)$ and $G_{12}$ is the shear modulus.

The analysis, by means of rosettes, of the strain field in a composite material is more complex than in isotropic materials. Various methods are available; a possible procedure is based on the following steps $[4,16]$ :

1 measurement of the strains $\varepsilon_{\mathrm{a}}, \varepsilon_{\mathrm{b}}, \varepsilon_{\mathrm{c}}$ given by the rosette grids;

2 calculation of the principal strains $\varepsilon_{p}, \varepsilon_{q}$ and of the angle $\theta_{p}$ (Figure 1 ) between the rosette reference axis (gauge $a$ axis in this case) and the maximum principal strain, $\varepsilon_{p}$, using the standard rosette relationships [17];

3 determination of the angle $\varphi_{\varepsilon}$ between the maximum principal strain $\varepsilon_{p}$ and the fibre direction 1 :

$$
\varphi_{\varepsilon}=\theta_{p}-\theta_{1}
$$

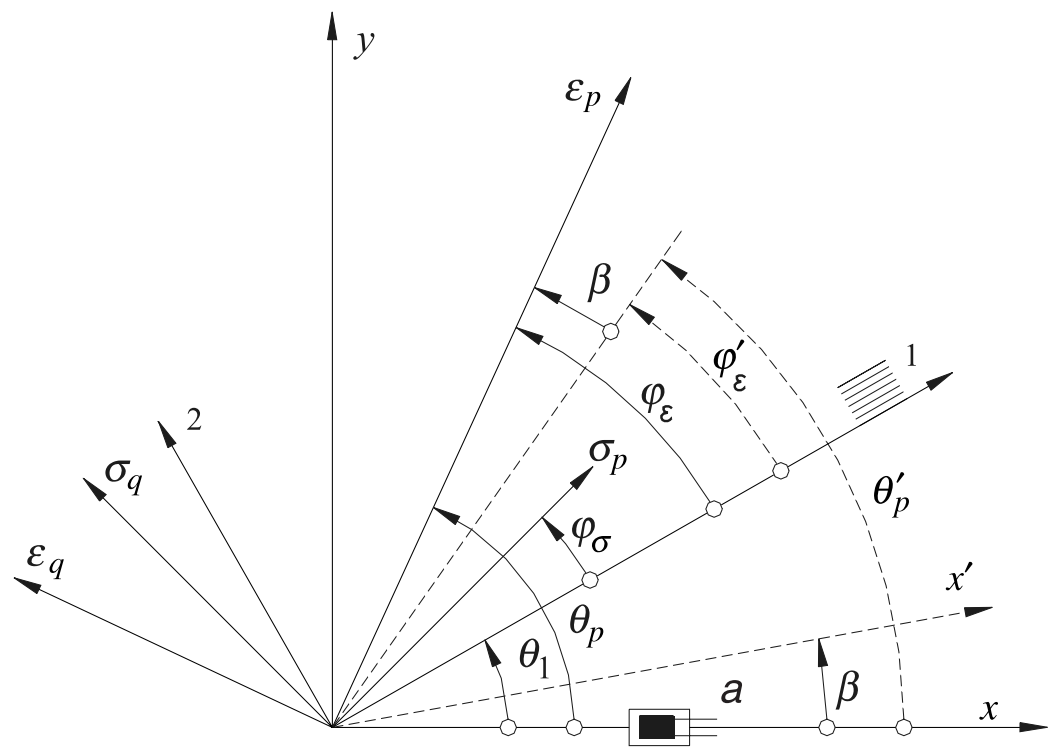

Figure I: Angle notations: $\beta$ is the misalignment angle of the rosette having gauge $a$ along the $x$ axis, other definitions are given in the Notation section (angles positive in the counterclockwise direction) 
where $\theta_{1}$ is the angle between the fibre direction and the rosette reference axis (gauge $a$ );

4 evaluation of the strains along the principal material directions by the strain transformation relationship [18]:

$\left[\begin{array}{c}\varepsilon_{1} \\ \varepsilon_{2} \\ \gamma_{12} / 2\end{array}\right]=\left[T\left(-\varphi_{\varepsilon}\right)\right]\left[\begin{array}{c}\varepsilon_{p} \\ \varepsilon_{q} \\ 0\end{array}\right]$

where the transformation matrix is given by

$[T(\theta)]=\left[\begin{array}{ccc}m^{2} & n^{2} & 2 m n \\ n^{2} & m^{2} & -2 m n \\ -m n & m n & m^{2}-n^{2}\end{array}\right]$

with $\theta=-\varphi_{\varepsilon}, m=\cos \theta, n=\sin \theta$.

\section{Errors along the principal material axes}

If the rosette is misaligned as a whole the new measured strains, $\varepsilon_{\mathrm{a}}^{\prime}, \varepsilon_{\mathrm{b}}^{\prime}, \varepsilon_{\mathrm{c}}^{\prime}$, still give exact values of the principal strains $\varepsilon_{p}, \varepsilon_{q}$, while the apparent angle between the $x$ axis (presumed position of gauge a) and the maximum principal strain becomes (Figure 1):

$\theta_{p}^{\prime}=\theta_{p}-\beta$

where $\beta$ is the misalignment angle of the rosette.

The apparent angle between the principal strain $\varepsilon_{p}$ and the fibre direction 1 is now:

$\varphi_{\varepsilon}^{\prime}=\theta_{p}^{\prime}-\theta_{1}$

Therefore from Equations (2) and (5) Equation (6) becomes:

$\varphi_{\varepsilon}^{\prime}=\varphi_{\varepsilon}-\beta$

The strains along the principal material axes are affected by errors because they are now given by the following relationship:

$\left[\begin{array}{c}\varepsilon_{1}^{\prime} \\ \varepsilon_{2}^{\prime} \\ \gamma_{12}^{\prime} / 2\end{array}\right]=\left[T\left(-\varphi_{\varepsilon}^{\prime}\right)\right]\left[\begin{array}{c}\varepsilon_{p} \\ \varepsilon_{q} \\ 0\end{array}\right]$

where the transformation matrix is still given by Equation (4), whereas the angle $\theta$ is now:

$\theta=-\varphi_{\varepsilon}^{\prime}$

The strain errors along the principal material directions from Equations (3) and (8) are:

$$
\varepsilon_{1}^{\prime}-\varepsilon_{1}=\frac{\varepsilon_{p}-\varepsilon_{q}}{2}\left[\cos 2\left(\varphi_{\varepsilon}-\beta\right)-\cos 2 \varphi_{\varepsilon}\right]
$$

$\varepsilon_{2}^{\prime}-\varepsilon_{2}=-\frac{\varepsilon_{p}-\varepsilon_{q}}{2}\left[\cos 2\left(\varphi_{\varepsilon}-\beta\right)-\cos 2 \varphi_{\varepsilon}\right]$

$\gamma_{12}^{\prime}-\gamma_{12}=\left(\varepsilon_{p}-\varepsilon_{q}\right)\left[\sin 2\left(\varphi_{\varepsilon}-\beta\right)-\sin 2 \varphi_{\varepsilon}\right]$

The previous relations show that the magnitude of strain errors along the principal material axes depend upon three factors:

- the difference between principal strains $\varepsilon_{p}-\varepsilon_{q}$;

- the misalignment installation error $\beta$ of the rosette;

- the angle $\varphi_{\varepsilon}$ between the maximum principal strain $\varepsilon_{p}$ and the fibre direction 1 .

The error is independent of rosette type and of rosette orientation with respect to the principal material axes. Figure 2 shows the strain errors versus the angle $\varphi_{\varepsilon}$ for the following misalignment angles: $\beta= \pm 5^{\circ}, \pm 7.5^{\circ}$, $\pm 10^{\circ}$. The maximum errors in normal strains are for $\varphi_{\varepsilon}= \pm 45^{\circ}+\beta / 2$, while the maximum errors in shear

(A)

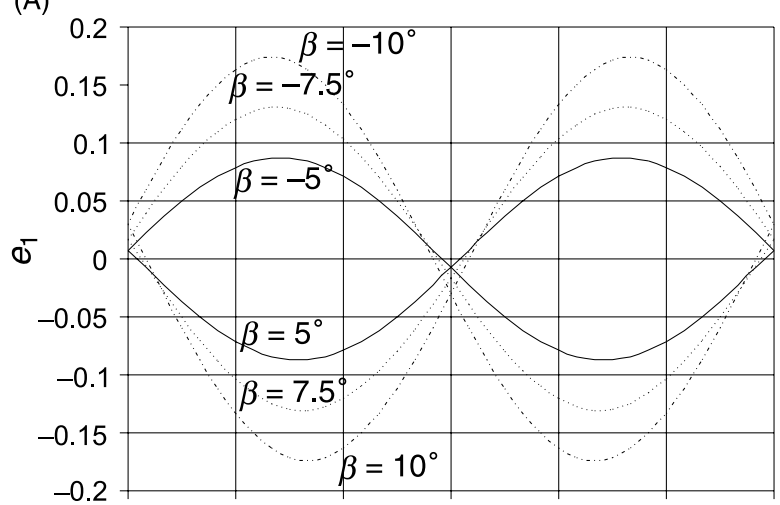

(B)

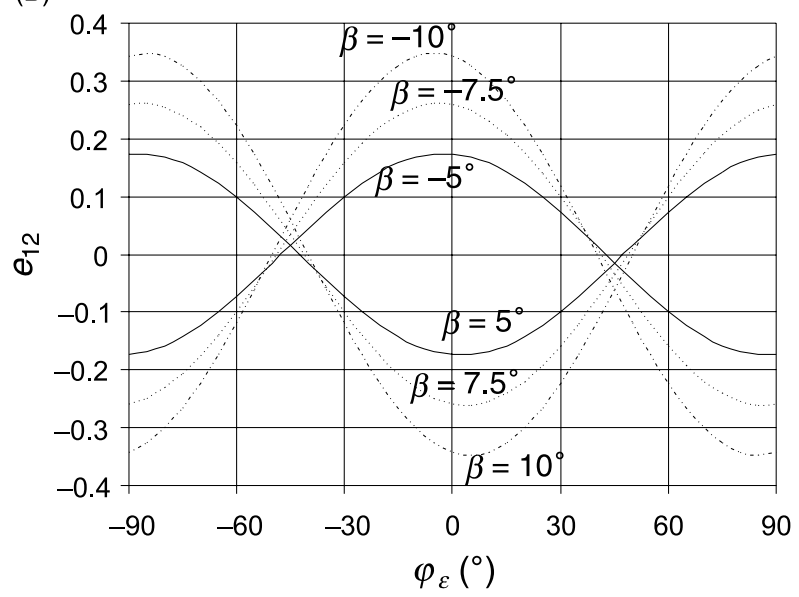

Figure 2: Errors, referred to the difference of principal strains, in (A) normal $\left(e_{1}=\frac{\varepsilon_{1}^{\prime}-\varepsilon_{1}}{\varepsilon_{p}-\varepsilon_{q}}=-\frac{\varepsilon_{2}^{\prime}-\varepsilon_{2}}{\varepsilon_{p}-\varepsilon_{q}}\right)$ and (B) shear $\left(e_{12}=\frac{\gamma_{12}^{\prime}-\gamma_{12}}{\varepsilon_{p}-\varepsilon_{q}}\right)$ strains versus the angle $\varphi_{\varepsilon}$ between the maximum principal strain and the fibre axis for various values of the misalignment angle $\beta$ 
strain are for $\varphi_{\varepsilon}=\beta / 2$ or $\varphi_{\varepsilon} \pm 90^{\circ}+\beta / 2$. However, considering only small misalignment errors, it is possible to evaluate the maximum errors that correspond to the following values of the angle $\varphi_{\varepsilon}: 0^{\circ}, \pm 45^{\circ}, 90^{\circ}$. Therefore, for $\varphi_{\varepsilon}=0^{\circ}$ or $90^{\circ}$, Equations (9)-(11) give

$\varepsilon_{1}^{\prime}-\varepsilon_{1}=\mp\left(\varepsilon_{p}-\varepsilon_{q}\right) \sin ^{2} \beta$

$\varepsilon_{2}^{\prime}-\varepsilon_{2}= \pm\left(\varepsilon_{p}-\varepsilon_{q}\right) \sin ^{2} \beta$

$\gamma_{12}^{\prime}-\gamma_{12}=\mp\left(\varepsilon_{p}-\varepsilon_{q}\right) \sin 2 \beta$

where the upper and lower signs refer to $0^{\circ}$ and $90^{\circ}$ respectively; for $\varphi_{\varepsilon}= \pm 45^{\circ}$ Equations (9)-(11) give

$\varepsilon_{1}^{\prime}-\varepsilon_{1}= \pm \frac{\varepsilon_{p}-\varepsilon_{q}}{2} \sin 2 \beta$

$\varepsilon_{2}^{\prime}-\varepsilon_{2}=\mp \frac{\varepsilon_{p}-\varepsilon_{q}}{2} \sin 2 \beta$

$\gamma_{12}^{\prime}-\gamma_{12}=\mp 2\left(\varepsilon_{p}-\varepsilon_{q}\right) \sin ^{2} \beta$

The previous relations and Figure 2 show that for small misalignments:

- the strain error in normal strains is maximum when the principal strain directions cross the principal material directions $\left(\varphi_{\varepsilon}= \pm 45^{\circ}\right)$;

- the strain error in shear strains is maximum when the principal strain directions and the principal material directions are coincident $\left(\varphi_{\varepsilon}=0^{\circ}\right.$ or $\left.90^{\circ}\right)$.

It is interesting to note that Equations (9) and (12) are equal to those obtained for a single strain gauge [7] provided that the angle $\varphi_{\varepsilon}$ is substituted by the angle between the chosen measurement direction and the maximum principal strain.

Taking into account Equations (3) and (9)-(11) and setting $r=\varepsilon_{q} / \varepsilon_{p}$, the relative errors are:

$\frac{\varepsilon_{1}^{\prime}-\varepsilon_{1}}{\varepsilon_{1}}=\frac{\cos 2\left(\varphi_{\varepsilon}-\beta\right)-\cos 2 \varphi_{\varepsilon}}{(1+r) /(1-r)+\cos 2 \varphi_{\varepsilon}}$

$\frac{\varepsilon_{2}^{\prime}-\varepsilon_{2}}{\varepsilon_{2}}=\frac{\cos 2\left(\varphi_{\varepsilon}-\beta\right)-\cos 2 \varphi_{\varepsilon}}{-(1+r) /(1-r)+\cos 2 \varphi_{\varepsilon}}$

$\frac{\gamma_{12}^{\prime}-\gamma_{12}}{\gamma_{12}}=\frac{\sin 2\left(\varphi_{\varepsilon}-\beta\right)}{\sin 2 \varphi_{\varepsilon}}-1$

These errors diverge when the reference strain tends to zero. For example, if $r=-1$ the relative error in normal
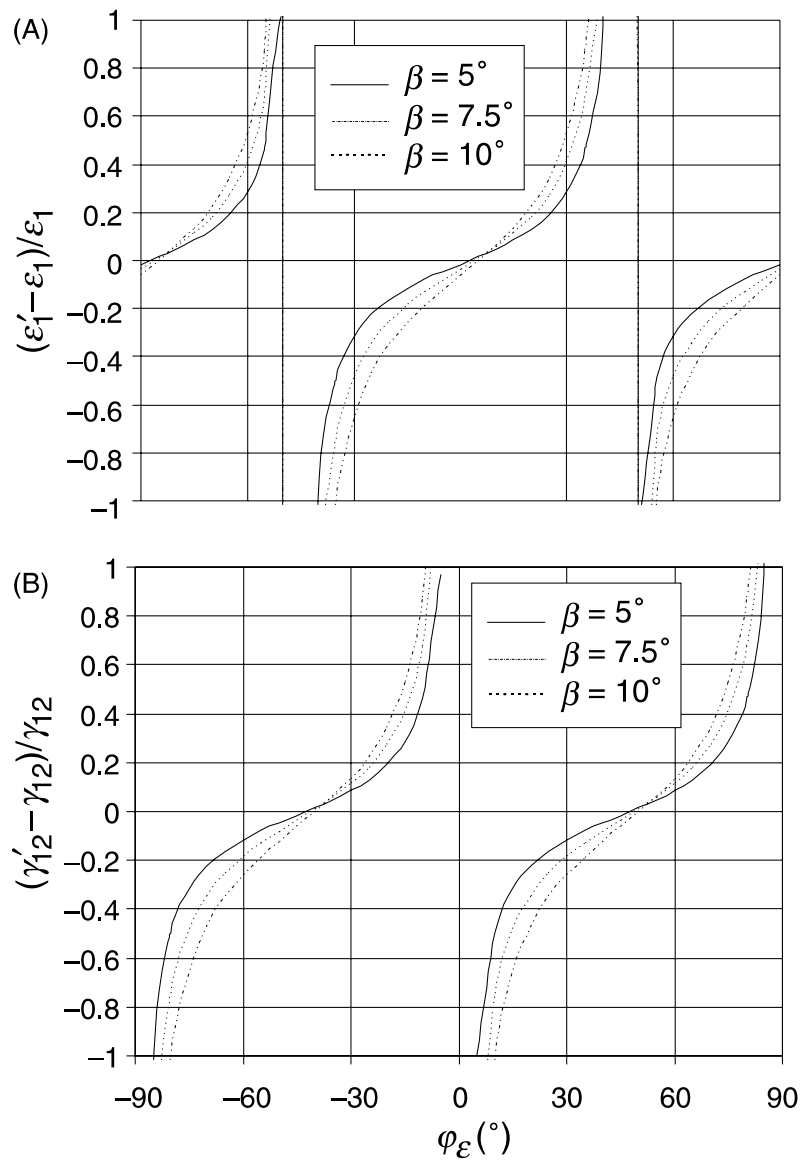

Figure 3: Relative errors associated with (A) normal (for $r=\varepsilon_{q} / \varepsilon_{p}=-1$ ) and (B) shear strains versus the angle $\varphi_{\varepsilon}$ for various values of the misalignment angle $\beta$

strains diverges when $\varphi_{\varepsilon}= \pm 45^{\circ}$, while the relative error associate with the shear strain diverges when $\varphi_{\varepsilon}=0^{\circ}$ or $90^{\circ}$ as it is shown in Figure 3 where the relative errors associated with the normal (for $r=-1$ ) and shear strains versus the angle $\varphi_{\varepsilon}$ are reported for the following misalignment angles: $\beta=5^{\circ}, 7.5^{\circ}, 10^{\circ}$. The previous analysis confirms that, although the strain measurement error is independent of the material, errors occur because the strains of interest are those along the principal axes of the material and not the principal strains, as for isotropic materials.

\section{Experimental Analysis}

The experiments were performed using three specimens obtained from the same GFRP unidirectional lamina, $2.5 \mathrm{~mm}$ thick. The plate used for specimens 1 and 2 was subjected to twisting loading (Figure 4). The first plate, referred to as specimen 1, has the principal material directions parallel to the edges (Figure 5A). In this condition $\varphi_{\varepsilon}=\varphi_{\sigma}=45^{\circ}$, $r=\varepsilon_{q} / \varepsilon_{p}=\sigma_{q} / \sigma_{p}=-1$. This specimen was instrumented with three rectangular rosettes $\mathrm{M}-\mathrm{M}$, type 


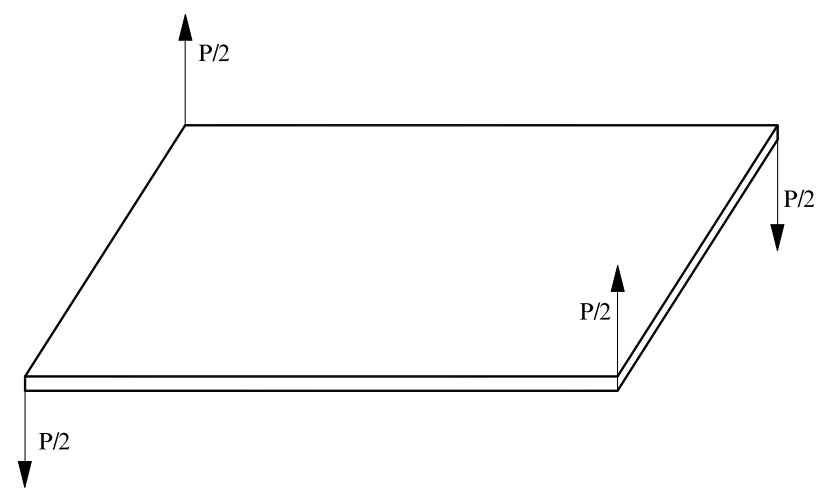

Figure 4: Loading for plate twisting specimen, i.e. for plates shown in Figure 5

CEA-05-250UR-350, having an active grid length of $L o=6.35 \mathrm{~mm}$ and an electrical resistance $R e=350 \Omega$. Figure $5 \mathrm{~A}$ shows that rosette 1 is aligned with the chosen measurement direction $\left(\beta=0^{\circ}\right)$, while rosettes 2 and 3 are bonded with angular mounting errors $\beta=+10^{\circ}$ and $\beta=-10^{\circ}$ respectively.

After the test the plate was machined in order to obtain specimen 2 (Figure 5B); small reinforcements were added in order to load the plate in the same manner as specimen 1 . In this case, the principal material directions were oriented along the diagonals of the plate. In this condition, $\varphi_{\varepsilon}=\varphi_{\sigma}=0^{\circ}, \sigma_{q} / \sigma_{p}=$ -1 . An additional rosette (0) was bonded to the plate with grid $a$ aligned without error $\left(\beta=0^{\circ}\right)$ along the fibre axis. Finally specimen 3 is a $10^{\circ}$ off-axis bar subjected to tensile loading. The specimen (Figure 6) was instrumented with two pair of rosettes installed on both sides of the test surface without misalignment error (rosettes 4, 4') and with misalignment error (rosettes 5, 5').

After the preliminary checks and loading cycles, at least three measurement cycles were performed for each specimen. The maximum load was $21.4 \mathrm{~N}$ for specimens 1 and 2 and $1430 \mathrm{~N}$ for specimen 3 . The strain readings were reproducible within 1-2 $\mu \mathrm{m} \mathrm{m}^{-1}$.

Table 1 shows the experimental results which are based on the average readings, at the maximum load, of three measurement cycles. The data for specimen 3 represent membrane strains obtained by the average values from rosettes $4-4^{\prime}$ and 5-5' respectively. Rows (4)-(6) show the measured strains, already corrected for transverse sensitivity effect. Rows (7)-(9) show the strains $\varepsilon_{1}, \varepsilon_{2}, \gamma_{12}$ along the principal directions 1,2 of the composite lamina, obtained for the aligned rosettes by means of Equation (3), while rows (10)-(12) give the values for the misaligned rosette obtained by means of Equation (8). Rows (13)-(15) show the experimental errors obtained by difference between misaligned and aligned strain values, whereas the rows (16)-(18) show the theoretical errors obtained using Equation (9)-(11), where the data from the aligned rosettes 1,0 and $4 / 4^{\prime}$, were used for the calculation concerning specimen 1,2 and 3 respectively. The agreements between theory and experimental results is satisfactory; the differences between experimental and theoretical errors are due to spurious influences.

As expected, for specimen $1\left(\varphi_{\varepsilon}=45^{\circ}\right)$ the larger error is for the normal strains, whereas for specimen 2 $\left(\varphi_{\varepsilon}=0^{\circ}\right)$ the larger error is for the shear strain. For the $10^{\circ}$ off-axis bar (specimen $3, \varphi_{\varepsilon}=-22^{\circ}$ ) both normal and shear strains experience large errors.

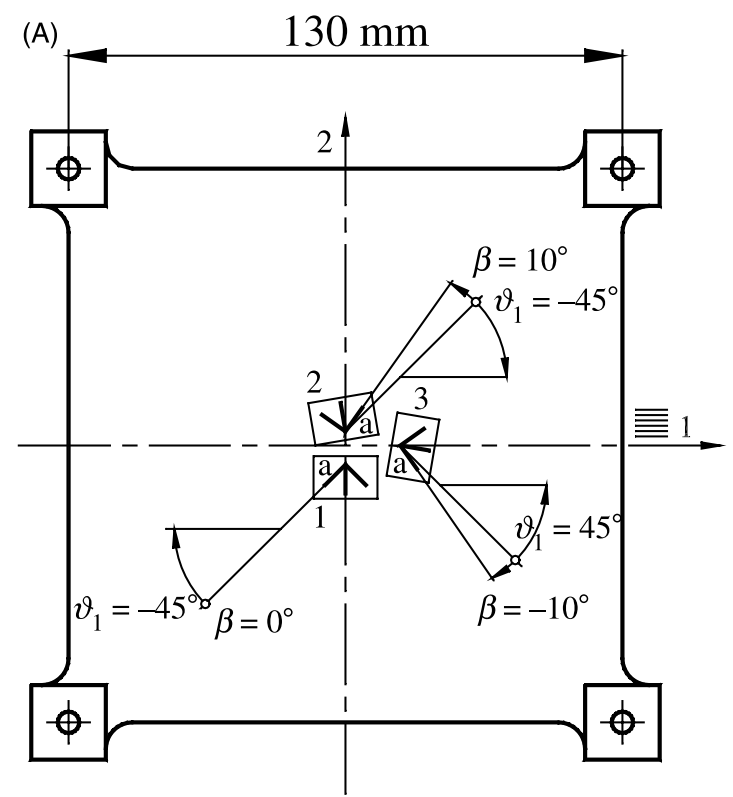

(B)

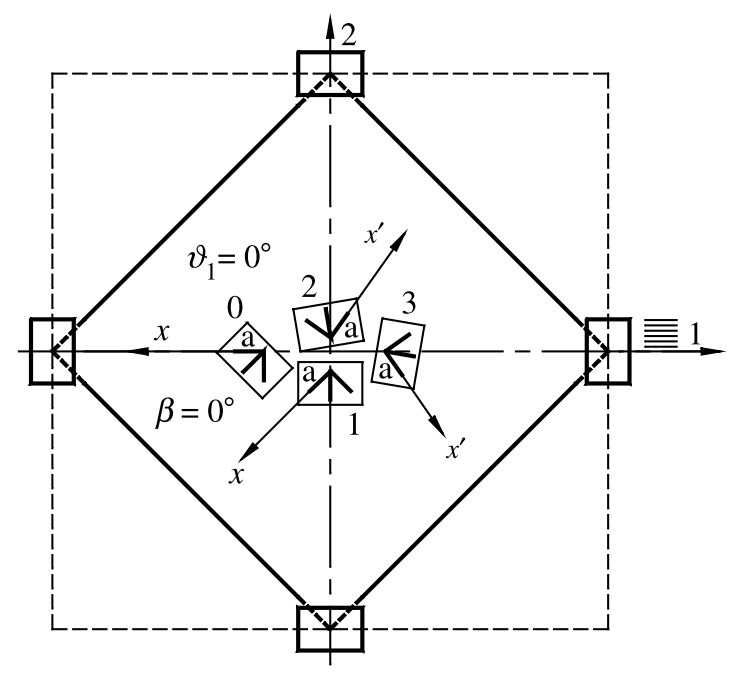

Figure 5: Geometry of the plates instrumented with aligned and misaligned rosettes: (A) specimen 1 with principal material directions along the edges, (B) specimen 2 with principal material directions along the diagonals $\left(\theta_{1}\right.$ is the fibre angle, $\beta$ is the rosette misalignment, as it is shown in Figure 1) 


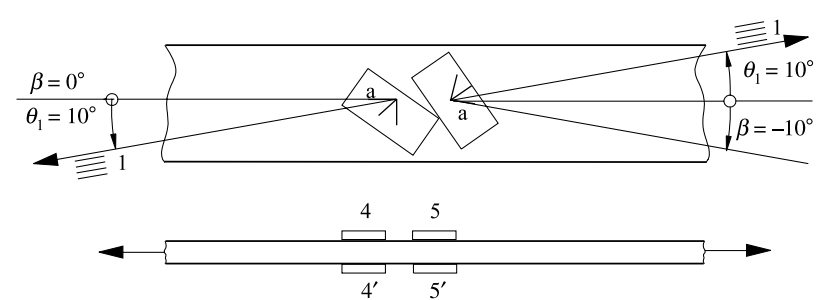

Figure 6: Off-axis tensile specimen, 3 , instrumented with aligned $\left(4 / 4^{\prime}\right)$ and misaligned $\left(5 / 5^{\prime}\right)$ rosettes $\left(\theta_{1}\right.$ is the fibre angle, $\beta$ is the rosette misalignment, as it is shown in Figure 1 )

\section{Conclusions}

In this paper the error due to the misalignment of a three gauge rosette on the determination of strains from composites was considered. Although the strain is a purely geometric entity, which therefore does not depend on the material properties, the determination of strains on composites requires attention as usually the information of interest relies on the strains along the material axes more than on the principal strains.
The theoretical analysis developed in this paper shows that the errors in the strains along the principal material directions depend on:

- the misalignment mounting angle of the rosette $\beta$;

- the difference between the principal strains, and

- the angle $\varphi_{\varepsilon}$ between the maximum principal strain and the fibre direction.

The analysis also shows that:

- the strain errors associated with the normal strains $\left(\varepsilon_{1}, \varepsilon_{2}\right)$ are maxima and opposite when the principal strains directions are at $45^{\circ}$ to the principal material directions;

- the strain error associated with the shear strain $\left(\gamma_{12}\right)$ is maximum when the principal strains and the material directions are parallel.

The previous analysis confirms that errors occur because the strains of interest are those along the principal axes of the material and not the principal strains as for isotropic materials.

The experimental results obtained with GFRP unidirectional specimens instrumented with rectangular

Table I: Experimental results for aligned $\left(0,1,4 / 4^{\prime}\right)$ and misaligned $\left(2,3,5 / 5^{\prime}\right)$ rosettes

\begin{tabular}{|c|c|c|c|c|c|c|c|c|c|c|}
\hline \multirow[b]{2}{*}{ Row } & \multirow[b]{2}{*}{ Experimental results } & \multicolumn{3}{|c|}{$\begin{array}{l}\text { Specimen I } \\
\text { (Figure 5A) } \\
\text { Rosettes }\end{array}$} & \multicolumn{4}{|c|}{$\begin{array}{l}\text { Specimen } 2 \\
\text { (Figure 5B) } \\
\text { Rosettes }\end{array}$} & \multicolumn{2}{|c|}{$\begin{array}{l}\text { Specimen } 3 \\
\text { (Figure 6) } \\
\text { Rosettes }\end{array}$} \\
\hline & & 1 & 2 & 3 & 0 & I & 2 & 3 & $4 / 4^{\prime}$ & $5 / 5^{\prime}$ \\
\hline I & Fibre angle, $\theta_{1}$ & $-45^{\circ}$ & $-45^{\circ}$ & $45^{\circ}$ & $0^{\circ}$ & $-45^{\circ}$ & $-45^{\circ}$ & $45^{\circ}$ & $10^{\circ}$ & $10^{\circ}$ \\
\hline 2 & Rosette misalignment, $\beta$ & $0^{\circ}$ & $10^{\circ}$ & $-10^{\circ}$ & $0^{\circ}$ & $0^{\circ}$ & $10^{\circ}$ & $-10^{\circ}$ & $0^{\circ}$ & $-0^{\circ}$ \\
\hline 3 & $\begin{array}{l}\text { Principal angle from fibre axis, } \varphi_{\varepsilon} \\
\text { Measured strains }\left(\mu \mathrm{m} \mathrm{m}^{-1}\right)\end{array}$ & \multicolumn{3}{|c|}{$45^{\circ}$} & \multicolumn{4}{|c|}{$0^{\circ}$} & \multicolumn{2}{|c|}{$-22^{\circ}$} \\
\hline 4 & $\varepsilon_{\mathrm{a}}$ & 329 & 288 & -311 & 118 & -101 & -156 & -156 & 522 & 561 \\
\hline 5 & $\varepsilon_{\mathrm{b}}$ & -5 & -120 & -112 & -82 & -328 & -292 & 117 & 22 & 143 \\
\hline 6 & $\begin{array}{l}\varepsilon_{\mathrm{c}} \\
\text { Strains along material axes I, } 2\left(\mu \mathrm{m} \mathrm{m}^{-1}\right) \\
\quad \text { (aligned rosettes) }\end{array}$ & -329 & -304 & 307 & -293 & -100 & -21 & -6 & -166 & -213 \\
\hline 7 & $\varepsilon_{1}$ & 4 & - & - & 118 & 127 & - & - & 448 & - \\
\hline 8 & $\varepsilon_{2}$ & -5 & - & - & -293 & -328 & - & - & -93 & - \\
\hline 9 & $\begin{array}{l}\gamma_{12} \\
\text { Strains along material axes I, } 2\left(\mu \mathrm{m} \mathrm{m}^{-1}\right) \\
\quad \text { (misaligned rosettes) }\end{array}$ & 659 & - & - & II & 0 & - & - & -527 & - \\
\hline 10 & $\varepsilon_{1}^{\prime}$ & - & 104 & -112 & - & - & 115 & 117 & - & 527 \\
\hline II & $\varepsilon_{2}^{\prime}$ & - & -120 & 108 & - & - & -292 & -279 & - & -179 \\
\hline 12 & $\begin{array}{l}\gamma_{12}^{\prime} \\
\text { Experimental error }\left(\mu \mathrm{m} \mathrm{m}^{-1}\right)\end{array}$ & - & 591 & 618 & - & - & -135 & 150 & - & -323 \\
\hline 13 & $\varepsilon_{1}^{\prime}-\varepsilon_{1}$ & - & 100 & -116 & - & - & -3 & -1 & - & 79 \\
\hline 14 & $\varepsilon_{2}^{\prime}-\varepsilon_{2}$ & - & -115 & 113 & - & - & I & 14 & - & -86 \\
\hline 15 & $\begin{array}{l}\gamma_{12}^{\prime}-\gamma_{12} \\
\text { Theoretical error }\left(\mu \mathrm{m} \mathrm{m}^{-1}\right)\end{array}$ & - & -68 & -41 & - & - & -146 & 139 & - & 204 \\
\hline 16 & $\varepsilon_{1}^{\prime}-\varepsilon_{1}$ & - & 113 & -113 & - & - & -12 & -12 & - & 73 \\
\hline 17 & $\varepsilon_{2}^{\prime}-\varepsilon_{2}$ & - & -113 & 113 & - & - & 12 & 12 & - & -73 \\
\hline 18 & $\gamma_{12}^{\prime}-\gamma_{12}$ & - & -40 & -40 & - & - & -141 & $|4|$ & - & 217 \\
\hline
\end{tabular}


rosettes mounted with and without misalignment error, confirm the theoretical predictions.

Both theory and experiments confirm the need for precise rosette alignment for reliable strain measurements from composite materials.

\section{ACKNOWLEDGEMENTS}

The research described in this paper was partly financed by the Italian Research Council (C.N.R.).

\section{REFERENCES}

1. Tuttle, M. E. and Brinson, H. F. (1984) Resistance-foil strain gage technology as applied to composite materials. Experimental Mechanics 24, 54-65; errata - corrigendum: Experimental Mechanics (1986) 26, 153-154.

2. Perry, C. C. (1984) The resistance strain guage revisited. Experimental Mechanics 24, 286-299.

3. Perry, C. C. (1988) Strain guage measurements on plastics and composites. Measurement Group Inc., Raleigh, NC.

4. Ajovalasit, A. (1995) Use of resistance strain gauges on composites (in Italian). Proc. 24th AIAS National Conf., Parma, 17-35.

5. Lanza di Scalea, F. (1998) Measurement of thermal expansion coefficients of composites using strain guages. Experimental Mechanics 38, 233-241.

6. Lanza di Scalea, F. (1998) Compensation of thermal output of strain guages on orthotropic materials: case of one compensating guage for multiple active ones. Experimental Techniques 22, 30-33.

7. M-M Tech. Note 511 (1983) Errors due to misalignment of strain gauges. Measurement Group Inc., Raleigh, NC.
8. Manson, S. S. and Morgan, W. C. (1946) Effect of misalignment of strain-guage components of strain rosettes. Nat. Advisory Commit. Aeronautics, Tech. Note 1133.

9. Hetényi, M. (1950) Handbook of Experimental Stress Analysis. John Wiley, New York, p. 425.

10. Rossetto, S., Bray, A. and Levi, R. (1974) Uncertainties and errors in magnitude and direction of principal strains evaluated with three-dimensional strain rosettes. Proc. 5th Int. Conf. Experimental Stress Analysis, Udine, 1.153-1.162.

11. Rossetto, S. and Levi, R. (1972) Analisi di alcune classi di errore nella determinazione sperimentale di stati di sollecitazione mediante rosette estensimetriche. Proc. 2nd AIAS National Conf., Genova, 323-351.

12. Tuttle, M. E. (1985) Error in strain measurement obtained using strain guages on composites. Proc. Fall Conf. Exp. Mech., Transducer Technology for Physical Measurements, SEM Bethel, CT, 170-179.

13. Tuttle, M. E. (1989) Fundamental strain-guage technology. In: Manual on Experimental Methods for Mechanical Testing of Composites (R. L. Pendleton and M. E. Tuttle, Eds). SEM, Bethel, CT, 17-26.

14. Bert, C. W. (1975) Experimental characterization of composite. In: Composite Materials, vol. 8. (L. I. Brouthman and R. H. Krock, Eds) Academic Press, New York, p. 73.

15. Greszezuk, L. B. (1966) In orientation effects in the mechanical behaviour of anisotropic structural materials. Am. Soc. Testing Materials, Philadelphia. STP 405, 1-13.

16. Anon (1984) Strain measurement on composite materials. Epsilonics $(M=M)$ 4, 10-11, 14-15.

17. Dally, J. W. and Riley, W. F. (1991) Experimental Stress Analysis, 3rd edn. McGraw-Hill, New York, p. 311.

18. Jones, R. M. (1975) Mechanics of Composite Materials. Hemisphere Publ. Corp., New York.

\section{BSSM}

Exhibition fees inc. refreshments and lunch on both days (one person), plus VAT:

Corporate 1 BSSM member:

Corporate 2 BSSM member/IOP SAVG member/IMechE member:

Individual member/non-member:

\section{$£ 145$}

$£ 218$

$£ 290$

Information for exhibitors: The exhibition will Visitors: Will be invited to view the exhibition begin at $9 \mathrm{am}$ on $10^{\text {th }}$ September and finish at $5 \mathrm{pm}$ free of charge, exhibitors are welcome to invite on $11^{\text {th }}$ September. A space of $2.5 \mathrm{~m}$ wide by $1 \mathrm{~m}$ visitors.

deep will be allocated for each stand. Social programme: Including a trip to Loch Venue: The Gilmorehill campus of Glasgow Lomond, conference dinner with a drinks University, at the same time as the IOP Stress reception at the Hunterian Museum. A social and Vibration Group's Conference. programme will also be arranged for partners of Accommodation: University hall of residence exhibitors!

accommodation or hotel accommodation upon Key Date: Deadline for registration to ensure request. programme: $31^{\text {st }}$ January 2003

For a registration form or for further information please contact:

Sally Cryer

16 Sweetlands Corner

Kents Hill

Milton Keynes MK7 6DR

Tel/fax: 01908559147 Email: sallybssm@mac.com 